\title{
The Influence of the Audience's Disposition towards Web Adverts on Product Awareness and Patronage
}

\author{
Oluwaseyi Williams, Thelma Ekanem , Idowu Sobowale and Lanre Amodu \\ Department of Mass Communication, Covenant University, Ota, Nigeria \\ Department of Mass Communication, McPherson University, Alapako, Nigeria
}

Correspondence should be addressed to: Lanre Amodu; lanre.amodu@covenantuniversity.edu.ng

Received date: 5 April 2017; Accepted date: 14 June 2017; Published date: 29 November 2017

Academic Editor: Ogunnaike Olaleke Oluseye

Copyright (C 2017. Oluwaseyi Williams, Thelma Ekanem, Idowu Sobowale and Lanre Amodu. Distributed under Creative Commons CC-BY 4.0

\begin{abstract}
This study investigates how the audience views online advertisements and the implication of this for the interest and patronage of the products advertised. The upsurge of the use of the Internet in Nigeria has inspired several online businesses. This is not surprising since businesses must move to where the customers are. The increased activities and time spent online by Internet users has also made the virtual space an appealing platform for advertisements. So alluring is the Internet that businesses that are not online also attempt to use web advertisements to pull customers to their physical shops. However, the audience may not be as receptive to these adverts as most businesses may expect. In fact, some Internet users tend to consider web advertisements as nuisances. Therefore, the objectives of this study are to find out the extent of audience's exposure to web advertisements, audience's disposition towards the advertisements, and how this disposition influences audience's attitude towards the product being advertised. The survey design was adopted with a sample size of 279 respondents. Analysis of the data suggests that not only were the respondents exposed to online adverts, they had a positive disposition towards the adverts and that influenced their purchasing decision.
\end{abstract}

Keywords: Web Advertisements, Awareness, Disposition, Patronage

Cite this Article as: Oluwaseyi Williams, Thelma Ekanem, Idowu Sobowale and Lanre Amodu (2017), "The Influence of the Audience's Disposition towards Web Adverts on Product Awareness and Patronage", Journal of African Research in Business \& Technology, Vol. 2017 (2017), Article ID 514539, DOI: 10.5171/2017. 514539 


\section{Introduction}

Advertising has become common place in the daily life of the modern society. Advertisements have permeated human existence to the extent that brands are projected through what people eat, what they wear, things they use, etc. In an attempt to describe the prevalence of advertising in the $21^{\text {st }}$ century, Katib (2015) quotes Huston Curtis thus:

A man wakes up in the morning after sleeping on an advertised bed, in an advertised pyjama, brushes with an advertised toothpaste, washes with an advertised soap, shaves with an advertised razor, have breakfast of advertised orange juice, cereal, toast and sips his advertised coffee and in an advertised mug, put on advertised clothes, and glances at his advertised watch. He rides to work in an advertised car, sits at an ad advertised desk and writes with an advertised pen. Yet, this man hesitates to advertise, saying that advertising does not pay. Finally, when his unadvertised business goes under, he will advertise for sale.

In Curtis' view, advertising is one of the most crucial commercial activities in the modern business environment. Companies advertise with the hope to have an edge over their competitors. A lot of investments go into making products breathtaking and desirable enough to spur patronage on the part of the consumer. Sadeghi et al (2015) mentioned that advertising is known for its long lasting impact on the consumer's mind.

With the advent of the Internet, Individuals and businesses are now engaging digital platforms to get their products and services to various audiences (Buckingham, 2003; Dominick, 2009). Once a consumer is connected onto the Internet, he or she has access to unlimited shopping opportunities. This had bridged the existing gap of time, traffic, and even cost as busy consumers can easily keep track on changing prices, products' availability and delivery services. The Internet also presents a new platform for advertisers to make known their goods and services to a global audience and as such, businesses are closer to their potential audiences than ever before (Jenkins, 2006).

The surge of web advertising has increased the need to find out how knowledgeable the audience is about online media usage. This will ascertain how online advertisements are viewed by members of the audience and how this influences their interest and patronage of the products advertised. Online media denote subjects that are accessible by electronic means (digital media formats) on websites or servers whereby features are able to be recovered through web browsers. Online media are thus a method of automated communication.

Hargittai \& Walejko (2008) explain that despite the seemingly unlimited opportunities available on the Internet for information sharing, there still exists a variation in people's engagement with digital media and they refer to this as the participation gap. Jenkins (2006), however, advocates that increased online media literacy education possesses the potential to close the digital media participation gap among the youth who are the main target of any digital marketing plan. The suggested media literacy education should provide the skills and opportunities that will enable active participation and understanding.

In a research carried by AdRelevance, a research company in the United States of America, it was revealed that $61 \%$ of the study participants clicked on web advertisements and purchased the products within 30 minutes of clicking and 38\% purchased within 8 to 30 days later (Saunders, 2000). Rayport \& Jaworski (2001) explain that the effectiveness of web advertisement could be measured in the following ways: impression, which is the number of times an ad is seen by viewers; leads, referring to when a viewer takes an 
action or makes an information request; sales, indicating the actual purchase,; and click through, which is the number of times viewers click on an advert.

As technology continues to evolve at a staggering speed, Internet users are also becoming more sophisticated in their online activities. This sophistication is necessitated by the ever growing online contents and sites contending for the limited attention of Internet users. In the same vein, online advertisers and marketer are forced to evolve new, competitive and less obvious ways of reaching their target audience. This study, therefore, examines what the audience thinks of the barrage of advertising messages encountered online and whether these messages create enough awareness to encourage purchase.

\section{Statement of the Problem}

Online advertising has experienced a rise in Nigeria because of the increased interfacing of the traditional media with the Internet. With the advancement of technology, there has been an increase in the use of the Internet by Nigerians (Sobowale, Amodu, Aririguzoh \& Ekanem, 2015), whose level of online media literacy is relatively high.

In order to stay competitive and relevant in the e-business environment, many virtual businesses have taken up many strategies to build online audience trust. Initial research reveals that this was done by tackling issues of trust building, privacy, quality, reputation and security (Wu, Hu \& Wu, 2010; Ha, 2012; Matthew, Ogedebe \& Ogedebe, 2013; Lakshmanan \& Basariya, 2015), however, none talked about online media literacy and its implications to capture and sustain the interest and patronage of products advertised.

Web ad plays a vital role in the lives of online audiences. It goes beyond mere entertainment to conveying information about products and services to the target audience. Asoto (2013) acknowledges that the majority of the Nigerian population is part of this audience. This is because there has been a significant increase in the usage of the Internet by Nigerians, thereby making them accessible to advents of digital devices such as smart phones, tablets, laptops and others. All these technological tools have access to the Internet and they attract more users to visit the Internet. Media consumption is changing too. The growth of convergent technology and social media has also brought more consumers online.

The Internet makes the Nigerian online consumers' lifestyle easier when shopping because they have access to several points of information, like accessing different online shops to compare prices before making a purchase, which was impossible a few years ago. They use the Internet to research before committing to a product and its purchase (Asoto, 2013). As such, advertisers nationally and globally have seen the rising need and opportunity to reach their target markets with messages through web advertisement. This also means that more business owners are spending more money on web advertising because of the continuous growth of Internet use in Nigeria.

Unfortunately, the rush to maximize the Internet opportunities by advertisers has flooded the web with so many adverts that tend to be uncomfortable for users. When this happens, Internet users may ignore web ads or even develop aversion for the products being advertised as a result of perceived Internet disturbance. This study, therefore, raises the following salient questions:

1. To what extent are residents of Lagos State, Nigeria exposed to web adverts?

2. What is their disposition towards the adverts?

3. How do their views of web advert influence their interest in online purchase? 


\section{Literature Review}

Bovee and Arens (1992) define advertising as a non-personal form of communication that is paid for by identified sponsors and is persuasive in nature; the services or ideas are usually sent out through the media. Moriarty, Wells and Mitchel (2009) explain that advertising also refers to all forms of communication techniques marketers use to reach customers, which in turn persuade these customers to make purchases.

A conspicuous attribute of advertising, as elucidated in the definition above, is the nonpersonal component. Advertising is considered non-personal because it is disseminated through the mass media to a large number of individuals, mostly at the same time and with no avenue for immediate feedback from the receivers (Belch and Belch, 2001). While it is quite convenient to reach thousands of people with the same message at about the same time, there arises the challenge of a unified message being appropriate for different individuals, considering their psychographic and demographic peculiarities.

Odun and Utulu (2016) observe that the introduction of the traditional media, particularly television, into advertising offered new opportunities for advertisements to become more real and interesting to the audience through the audio-visual capabilities. With time, however, advertising inherited the limitations of the traditional media, chief among which are inaccessibility and low interactivity. The audience was becoming more sophisticated and selective in its message consumption therefore necessitating the adoption of a more dynamic means of communicationInformation and Communication Technology.

Amodu (2008) describes Information Communication Technology (ICT) as a revolutionary advancement that creates a "next door" effect through the elimination of distance. According to Amodu, "ICT presents an experimental ground that is only limited by the imagination and creativities of its users". The application of ICT, particularly the Internet, to advertising opened up more imaginative ways of reaching the audience. The Internet has created a higher level of interactivity between the advertisers and the audience beyond what was previously available.

Despite the seemingly unlimited possibilities of interaction on the Internet, it has also been argued that interactivity should not be solely credited to the Internet because the traditional media- television, radio, newspapers, etc - have always possessed the attribute (Karimova, 2011). While explaining the interactive nature of the traditional media, Karimova (2011) states that consumers can be actively involved in interpreting advertising messages. Interaction takes place between the advertiser and the audience as the former creates the advertising messages and the latter decodes the meaning. Karimova also argues that the audience may decide what to do with the advertising messages beyond what the advertisers intend such amusement, entertainment and art collection. Karimova's argument is, however, not adequate to justify the interactivity of the traditional media because it describes the advertisers as being confined to one side and the audience is confined to the other side with advertising in the middle as a mediator. At best, there can only be an inferred interactivity since both sides interact with the advert and instead of each other. Also, the advertisers are left to decide the success of their messages through purchase and not through direct response as available in the case of the Internet.

Baran (2002) observes that in mass communication, feedback is traditionally described as delayed and inferential, however, the Internet has changed this by making feedback immediate and direct. This is perhaps the reason advertisers are capitalizing on the opportunity to directly reach their audience and receive immediate response through the use of web advertisements or web ads. 
Chaffery, Mayer, Johnston and Ellis-Chadwick (2003) explain that web ads are a form of online advertising that entails embedding an advertisement into a web page. It is intended to attract traffic to a website by linking to the website of the advertiser. These ads are seen popping up at the top, side, bottom or other positions of most Web pages. In addition, web advertisements are graphic buttons that carry texts or writings that are intended to pull the audience's attention and prompt a response or feedback. They persuade the audience to access the advertiser's home page through the banner ads.

Certain web pages display over two web advertisement for every web page, and some even go as far as to use a software program to alternate banners every few minutes while a visitor remains on a specified website. The following types of web ads have been identified:

\section{Text Ads}

Text ads are widespread in newsletters and rich site summary (RSS) feeds. On many websites, text advertisements stand as the foremost kind of Internet advertising today. Certain products need a few words instead of pictures. Text ads comprise limited lines of text with a link or an email for participation (Asoto, 2013). They are valued on a cost per mill or cost per click basis. The challenge with this type of web ads is in trailing the number of ads that has been shown on a website. The most popular example of text ads is Google's Adsense program, which delivers contextually relevant text ads (ads targeted based on the content of a page) and is in use by thousands of websites worldwide.

\section{Interstitials}

These are ads shown in the transition between two pages of a site. It is a part of the main browser window. When clicking on a web page on Page A, but rather than going to Page $B$, an in-between ad page comprising of a sales pitch will be seen. Interstitials are becoming popular with advertisers because of its almost unrestricted amount of space advertisers can use to pitch a product to the audience.

\section{Pop Up Ads}

Pop-up ads entail a small window that "pops up" over the main browser window when entering a site. The pop-up windows can encompass text, graphics and forms to collect information or email addresses. There are two flaws in pop-up ads:

- $\quad$ From a webmaster's standpoint, popup ads wrench control of the browser from their own page, and some badly-written popup ads may also crash certain browsers, leaving a bad impression on a viewer's mind.

- From an advertiser's viewpoint, most pop-up windows can be minimized (hidden behind other windows) with relative ease, so, if the pop-up window is being used to rotate ads on a periodic basis, the advertisement may not be noticeable but it is still getting paid for.

\section{Opt-in Mailing}

This kind of ad is promptly becoming dominant among Nigeria online marketers. Opt-in mailing comprises sending an email to a "pre-qualified" list of individuals (target audience) that have shown interest in receiving information on a given subject. Some websites sell their lists of newsletter recipients to advertisers, but most choose to keep the email addresses secret and allocate the ad on the advertiser's behalf.

Opt-in mailing is different from SPAM. SPAM is an alternative term for bulk mails, and includes sending messages to individuals who have never shown interests in receiving them. Some companies claim to be opt-in mailing but they are trading SPAM services. 


\section{HTML Ads}

HTML ads combine graphics and text with other HTML elements such as pull-down list, check boxes or forms. This can be operative in getting traffic, but are much harder to serve and track, and generally require sophisticated software to run.

Other forms of web ads include:

1. Rich Media ads: These ads make use of multimedia elements such as sound, animation (plug-ins such as Shockwave or Flash) and Java/JavaScript to drive the message home.

2. Hybrid Ads: These are a combination of some aspects of other advertising types, such as text and banners, to make a more effective pitch to visitors.

3. Sponsorship and Partnership: This involves putting the advertising more fully into the homepage of a website.

Above are examples of the opportunities available through web ads to reach specific audience and obtain specific responses. One of the most significant attributes of web ads is the avenue for data gathering on the audience who respond to the ads, their needs and what other products they may be interested in. This aids target marketing in which messages are designed for a narrowly defined group of individuals and waste of coverage is minimized (Belch and Belch, 2001).

Nevertheless, Belch and Belch (2001) still observe that web advertising is not without its attending challenges. For instance, the constant growth of Internet users results in frequent changes in audience characteristics. This implies that data are often outdated before they can be put to meaningful use. There is also the problem that comes with the proliferation of ads on the Internet. Not only is there a high possibility that some ads may not be noticed, Internet audience also tends to be irritated by the clutter.

\section{Theoretical Framework}

The uses and gratification theory was adopted for this study. The theory was developed by Katz, Blumler and Gurevitch to explain what the audience does with the media instead of what the media do to the audience (Egede \& Chuks-Nwosu, 2013). The theory focuses mainly on the audience's functional use of the media. It posits that members of the audience seek out the mass media for the purpose of satisfying individual needs.

According to Blumler and Katz (1974), media consumers exercise the liberty to choose how they use media contents and how those contents affect them. The audience is seen as having the ability to selectively choose, attend to, perceive and retain media messages based on his/her needs or requirements (Folarin, 2005). The uses and gratification theory shifts our attention from how media messages are produced and transmitted to how they are consumed and for what purpose.

While illustrating how the theory works, Basking, Aronoff and Lattimore (1997) explain that everyone is not regularly exposed to news papers, television, radio or even Facebook at the same time and rate. Rather, people choose when and for how long they are exposed to them. The authors identify that some of the ways people use the media include for entertainment, scanning the environment for items that are personally important, diversion, substitution of personal relationship and a check on personal identity.

Considering the focus of this theory on audience's use of the media being determined by their perceived gratification, this theory is very valuable to our current study. Advertisers place web ads because of their awareness of the interactivity of the Internet and the consistent growth of Internet users. However, having access to a huge number of consumers does not guarantee that web ads will be viewed and responded to because of 
the active role of the audience. The uses and gratification theory shows that first, the audience may not access the advert message at the same time or in the same way and second, the audience may choose to use the web ads for other purposes other than the original intention of the advertisers, which may include for entertainment or amusement.

\section{Methodology}

This study adopted the survey method to investigate what the residents of Lagos State, Nigeria think about web adverts. Lagos State is a major commercial centre of Nigeria where there is a high concentration of businesses, customers and advertising. The infrastructure to access the Internet is also readily available in Lagos. The study was carried out at Ikorodu West Local Government Council Development Area. Ten (10) major streets were identified in the area and three (3) houses with one (1) respondent in each house were selected from each street, making a total of 300 respondents. The houses were selected through the systematic random sampling technique. Out of the 300 copies of the questionnaire that were administered, only 279 were properly filled and usable for this study.

\section{Results}

Based on the analysis of the 279 reliable responses, results were generated and they are presented below:

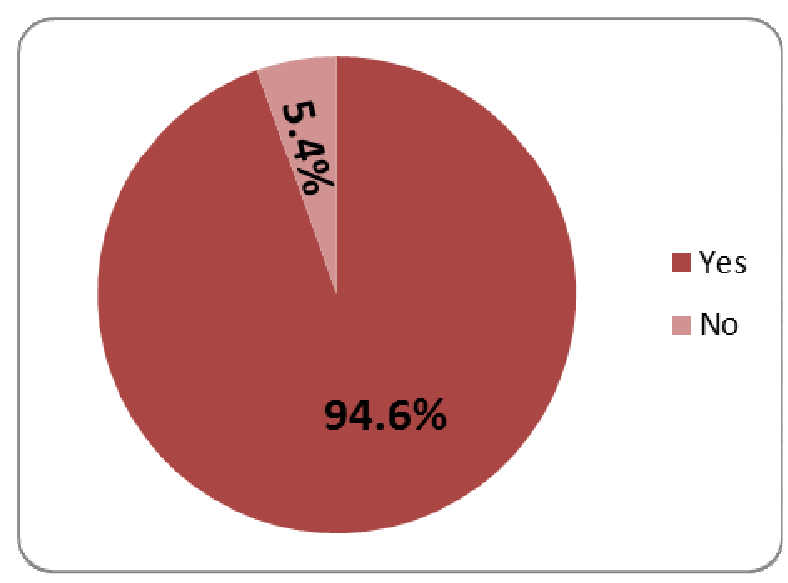

Fig. 1: Usage of the Internet

To find out the exposure of the respondents to web advertisements (ads), it was necessary to first establish their use of the Internet. Fig. 1 shows that almost the entire respondents used the Internet. This result confirms the availability of the Internet to the respondents, which will in turn create an avenue for them to see and perhaps respond to web ads. 


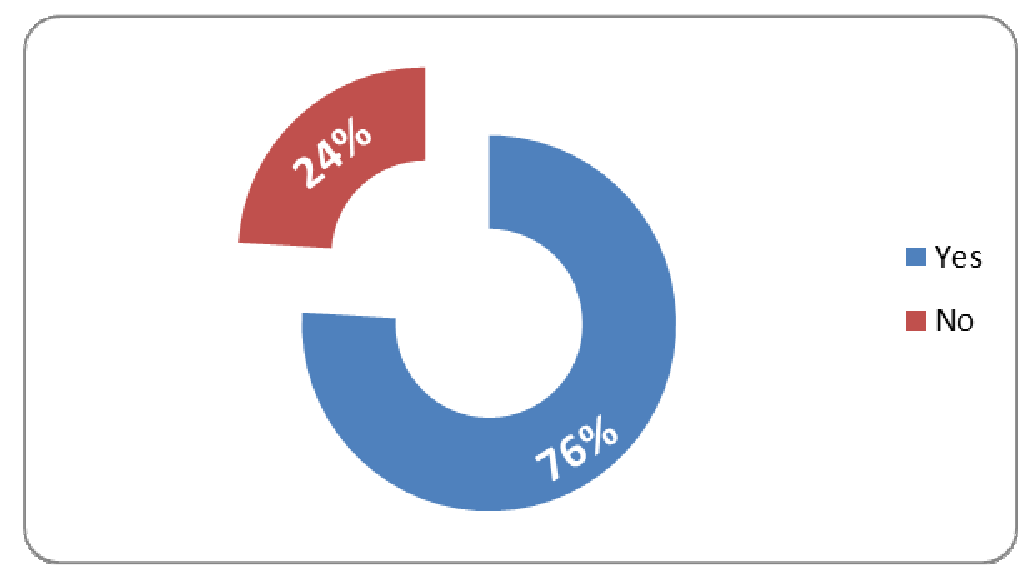

Fig. 2: Respondents' familiarity with web advertisements

The figure above shows that more than three-quarters of the respondents were familiar with web advertisements while $24 \%$ were not. This result shows the popularity of web advertisements and indicates that they were noticeable to majority of our respondents.

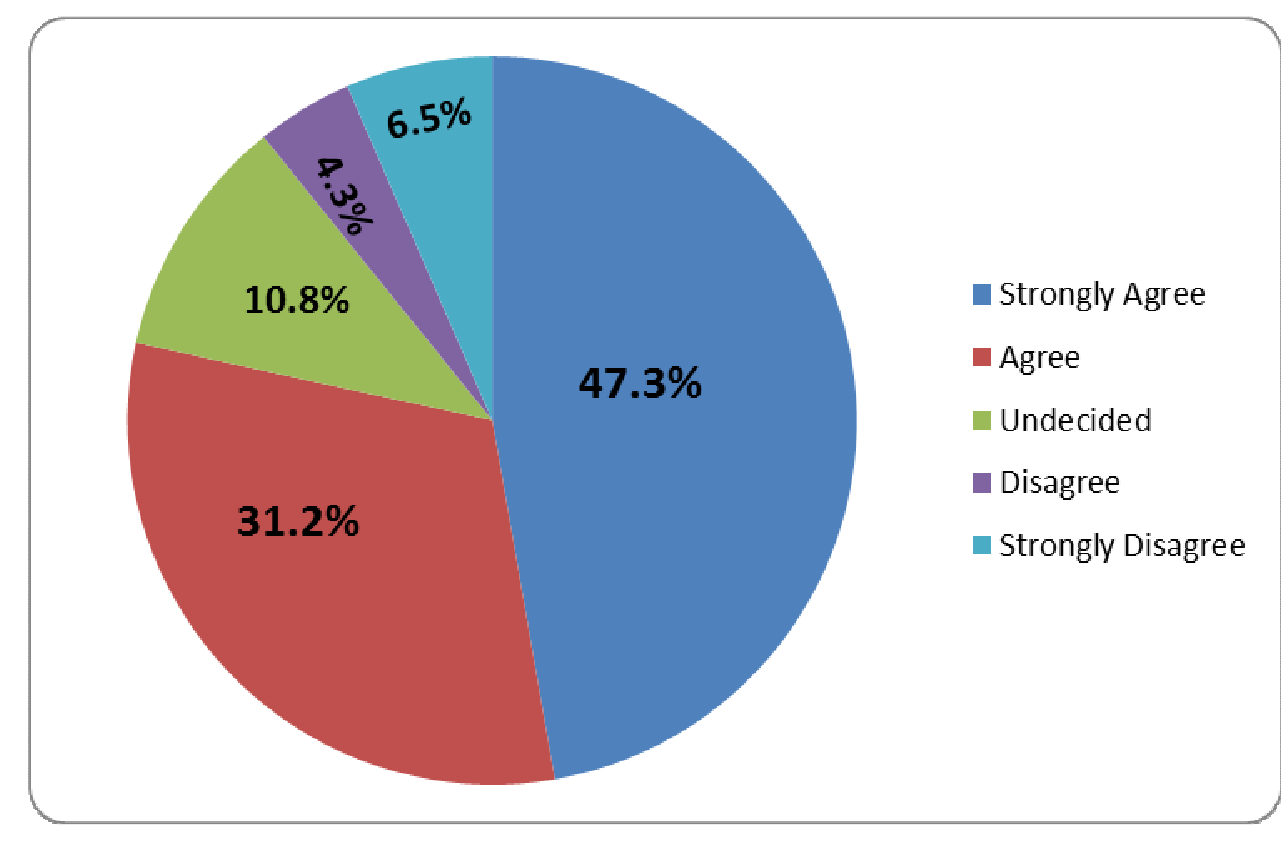

Fig. 3: Respondents' ability to identify web advertisements

Respondents were asked about their ability to identify web advertisements when encountered and majority of them were positive that they could do so. This confirms that web advertisements were obvious enough not to be mistaken for any other message. 


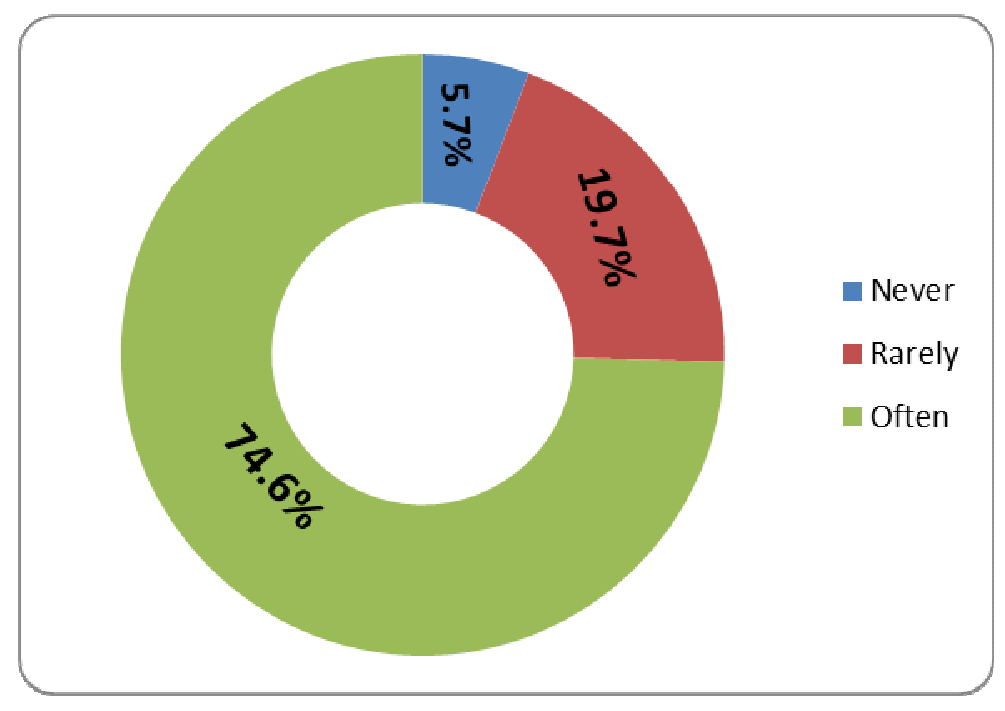

Fig. 4: Respondents' frequency of seeing web advertisements

To further confirm the respondents' exposure to web ads, they were asked how frequently they saw the ads whenever they were online. Fig. 4 reveals that majority of the respondents saw the ads severally. Almost three-quarters (74.6\%) of them had a high exposure to web advertisements by seeing the ads often.

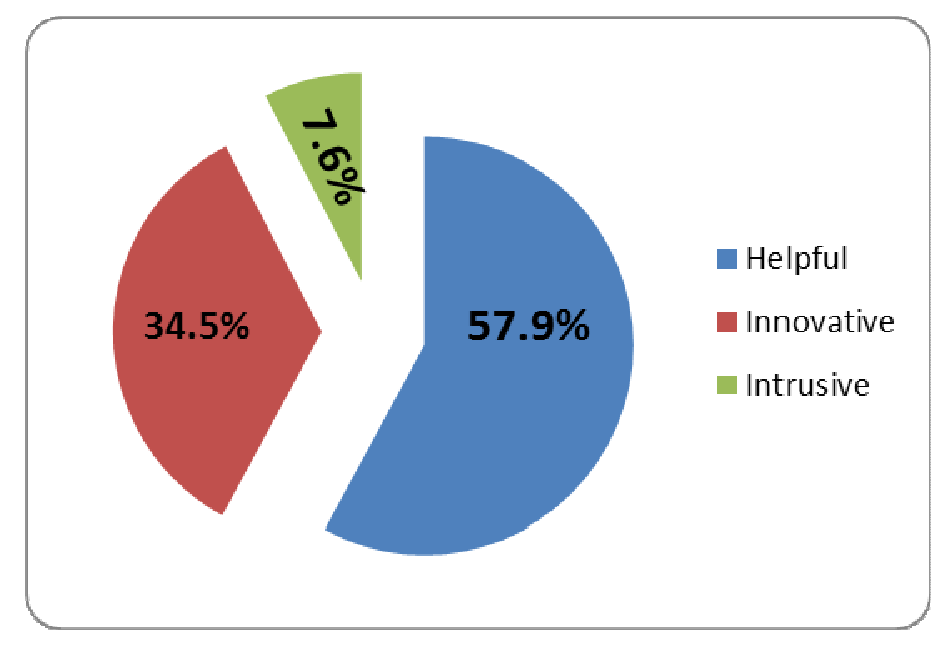

Fig. 5: Respondents' views of web advertisements

Fig. 5 elucidates how respondents viewed web advertisements. A larger percentage, $57.9 \%$ and $34.5 \%$ respectively, viewed the ads as helpful and innovative. This shows that respondents had positive disposition towards web advertisements. Thus, there is an opportunity for advertisers to optimize the use of web advertisements. 
Table 1: Response to web advertisements

\begin{tabular}{|c|c|c|}
\hline Responses & \multicolumn{1}{|c|}{$\begin{array}{l}\text { I visit the websites } \\
\text { because of web ads }\end{array}$} & $\begin{array}{c}\text { Web ads determine my level } \\
\text { of involvement in online purchase }\end{array}$ \\
\hline Strongly agree & 30.1 & 35.1 \\
\hline Agree & 17.2 & 24.7 \\
\hline Undecided & 12.9 & 17.2 \\
\hline Disagree & 24.7 & 9.3 \\
\hline Strongly Disagree & 15.1 & 13.6 \\
\hline Total & $\begin{array}{l}\mathbf{1 0 0 \%} \\
\mathbf{n = 2 7 9}\end{array}$ & $\begin{array}{l}\mathbf{1 0 0 \%} \\
\mathbf{n = 2 7 9}\end{array}$ \\
\hline
\end{tabular}

Table 1 show that almost half of the respondents were positive that they followed web advertisements to the websites linked to them. This percentage $(47.3 \%)$, which is a combination of those who strongly agreed and agreed, demonstrates the respondents' attraction towards the adverts and their interest to get more details from the websites. The table also shows that more than half of the respondents were positive that web advertisements determined how involved they were in online purchase.

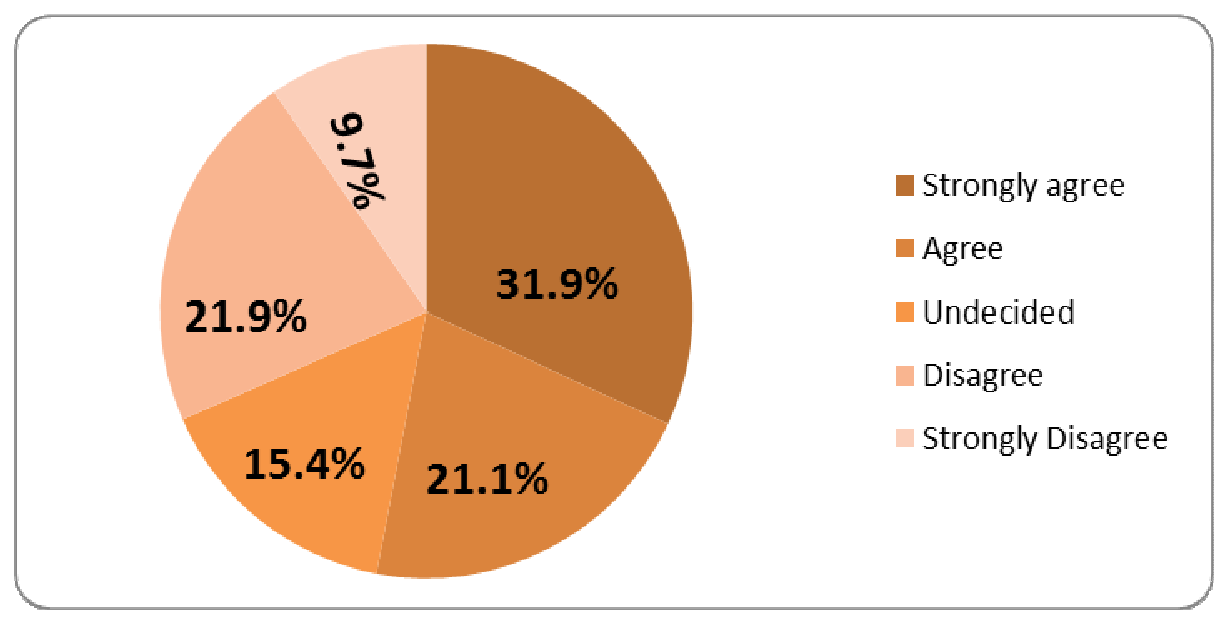

Fig. 6: Influence of web adverts on purchase decision

This figure shows that more than half of the respondents claimed that web advertisements influenced their purchasing decision. This can be seen from the combination of those who strongly agreed and agreed (53\%). The fact that those who strongly agreed with the statement had the highest single percentage showed that web advertisements have been considerably successful in influencing purchase among our respondents.

\section{Discussion}

The Internet has proved to be a fertile ground for advertising. It has provided a viable means of reaching the audience directly, personally and in a timely manner. According to Moriarty, Wells and Mitchel (2009, p.340), "the most important advertising-related role that the Internet plays is to provide information. The internet has developed into a giant online library for 
consumers". Web ads help to provide information on millions of products and services to consumers. Nevertheless, the audience must consider the information needed and beneficial before it can appreciate the advertising messages.

The first research question of this study aimed to investigate the extent to which residents of Lagos State, Nigeria were exposed to web adverts. First, the respondents were asked if they used the Internet and $94.6 \%$ of them affirmed that they did (Table 1). This result laid the foundation for further investigation into their exposure to web advertisements since they were required to be Internet users to be able to access the adverts. The study also revealed that more than three-quarters of the respondents $(76 \%)$ were familiar with web adverts (Table 2). Furthermore, $47.3 \%$ and $31.2 \%$ strongly agreed and agreed respectively that they could identify web adverts among other contents on the Internet. Again, when asked about the frequency of them seeing web advertisements while online, $74.6 \%$ of the respondents said they saw the ads often. Based on the findings of this study, therefore, it is evident that the respondents for this study were majorly Internet users and they were exposed to web advertisements.

The study also sought to know the disposition of the respondents towards the web advertisements they were exposed to. The results show that $57.9 \%$ of them considered the ads helpful, meaning that the ads assisted in solving some needs; $34.5 \%$ considered the ads innovative, meaning that they appreciated the concepts of the ad; while a negligible $7.6 \%$ found the web advertisements intrusive (Table 5). Consequently, the result suggests that the majority of our respondents had a positive disposition towards the web advertisements they were exposed to online. This confirms the findings of Schlosser, Shavitt and Kanfer (1999) that the perception of Internet users towards Internet advertising was generally positive. This result also supports the theoretical foundation laid for this study. By showing that the respondents did not react to web ads the same way, the study agrees with the uses and gratification theory that people respond to media messages based on the benefits they expect to derive. While some respondents perceive web ads to be helpful and innovative, some still consider them intrusive.

The final research question was to find out how the respondents' view of web advertisements had influenced their online purchase decision. The results revealed that almost half of the respondents (47.3\%) followed web ads to the websites of the sponsor. This shows a considerable level of interest that can potentially lead to purchase. Furthermore, more than half of the respondents (53\%) claimed to have been influenced by web advertisements in the purchasing decision. This result is particularly important since those who held a negative view were only $31.6 \%$, with $15.4 \%$ undecided. Of course, marketers know that undecided audience can be won over with the right message and offer. This research, therefore, reveals that web advertisements are useful in our respondents' purchasing decisions.

\section{Conclusion and Recommendation}

As the Internet continues to increase in penetration and adoption, greater opportunities are created to reach the global audience with precision that has never been witnessed before. More products and services are advertised online with significant amount of money being spent. It becomes necessary, therefore, to investigate the extent to which the target audiences are exposed to the web adverts, their dispositions towards those adverts and the possibility of the ads influencing their purchasing decision. This study reveals that residents of Lagos State, Nigeria were quite familiar with Internet advertisements. Also, the majority of them had a positive disposition towards the web adverts and they were influenced by the adverts in their 
purchasing decision. This study, therefore, recommends the following:

1. Web advertisers should optimise the opportunity available through the goodwill of Internet users. Since it was discovered that our respondents appreciated helpful and innovative web advertisements, advertisers should intensify efforts to display relevant advertising messages to the relevant audience in very creative and innovative way.

2. Taking a cue from the uses and gratification theory, web advertisers should take into consideration the various needs of their target audience and tailor their messages to meet such needs.

\section{Acknowledgement}

We like to acknowledge Covenant University, Ota, Ogun State, Nigeria for sponsoring our participation in this conference and the publication of the paper.

\section{References}

1. Amodu, L O. (2008), The role of internet in the sustainable development of rural Africa: A fact or a farce? In V. Mojaye, 0. Oyewo, R. M'bayo, and I. Sobowale, (Eds), Health communication, gender violence and ICTs in Nigeria (pp. 285-296). Ibadan, Nigeria: University Press.

2. Asoto, D. (2013). "Nigeria online advertising and benefits of Internet marketing and campaign," [Online], [Retrieved August 5, 2016], http://asotoadeola.com/2010/12/onlineadvertising-in-nigeria-overview-of-trendschallenges-benefits /

3. Armstrong, S. (2001). Advertising on the Internet. USA: Kogan Page Limited

4. Baskin, O., Aronoff, C. and Lattimore, D. (1997). Public relations: The profession and the practice. New York: McGraw-Hill Companies, Inc.
5. Belch, G. and Belch, M. (2001). Advertising and promotion: An integrated marketing communications perspective $\left(5^{\text {th }}\right.$ ed). New York: McGraw-Hill Companies, Inc.

6. Bovee, C. L. and Arens, W. F. (1992). Contemporary advertising (4th ed.). Homewood, Illinois: Irwin Inc.

7. Blumler, J. and Katz, E. (1974). The uses of mass communication. Beverly Hills, CA: Sage Publication.

8. Buckingham, D. (2003). Media Education: Literacy, Learning and Contemporary Culture. Cambridge, MA: Polity Press.

9. Chaffery, M. J. and Ellis-Chadwick. (2003). Internet marketing: Strategy, implementation and practice. England: Pearson Education Limited.

10. Dominick, J. R. (2009). Dynamics of mass communication: Media in the digital age (10 ${ }^{\text {th }}$ ed.). Boston: McGraw-Hill.

11. Egede, E. and Chuks-Nwosu, E. (2013). Uses and gratification theory and the optimization of the media in the privatization of the state owned enterprises in Nigeria. Journal of Economics and Sustainable Development, 4(16), 202-212.

12. Folarin, B. (2005). Theories of mass communication: An introductory text. Ibadan, Nigeria: Bakinfol Publications.

13. Ha, L. (2012). Online advertising research in advertising journals: A review. Journal of Current Issues \& Research in Advertising, 30(1), 31-48.

14. Hargittai, E. and Walejko, G. (2008). The participation divide: Content creation and sharing in the digital age. Information, Communication \& Society, 11(2), 239-256.

15. Jenkins, H. (2006). Convergence culture where old and new media collide. New York: New York University. 
16. Katib, I. (2015). Advertising is functional, [Online], [Retrieved August 5, 2016],

https://www.thenigerianvoice.com/news/1 97828/advertising-is-functional.html.

17. Lakshmanan, D. and Basariya, S R. (2015). Factors affecting the effectiveness of advertising in the current scenario Advertising factors are immune to business which aspire to inspire before you expire. International Journal of Science and Research (IJSR), 6(1), 1264-1267.

18. Matthew, J., Ogedebe, P M. and Ogedebe, S. M. (2013). Influence of web advertising on consumer behaviour in Maiduguri metropolis, Nigeria. Asian Journal of Social Sciences \& Humanities, 2 (2), 548557.

19. Moriarty, S. E., Wells, W. and Mitchell, N. (2009). Advertising: Principles \& practice. UK: Pearson Prentice Hall.

20. PR2 Free Website Promotion Course. (2007). [Online], [Retrieved August 5, 2016], www.pr2.com

21. Rayport, J. F. and Jaworski, B. J. (2001). E-commerce. California: McGrawHill/Irwin MarketspaceU.

22. Saunders, C. (2000). Numbers show signs of online ad slowdown, [Online],
[Retrieved August 5, 2016], http://cyberatlas.internet.com/markets/adv ertising/print/0,5941_542091,00.html

23. Sadeghi, M., Fakharyan, M., Dadkhah, R., Khodadadian, O R., Vosta, S N. and Jafar, M. (2015). Investigating the effect of rational and emotional advertising appeals of hamrahe aval mobile operator on attitude towards advertising and brand attitude (Case study: student users of mobile in the area of Tehran). International Journal of Asian Social Science, 5(4), 233-244.

24. Schlosser, A., Shavitt, S. and Kanfer, A. (1999). Survey of internet users' attitude towards internet advertising. Journal of Interactive Marketing, 13 (3), 34-54.

25. Sobowale, I., Amodu, L., Arriguzoh, S. and Ekanem, T. (2015), 'The Internet as a tool for information and education: The case of Ota Community in Nigeria,' Proceedings of EDULEARN15 Conference, ISBN: 978-84606-8243-1, 6-8 July 2015, Barcelona, Spain, 8232-8240.

26. Wu, G., Hu, X. and $\mathrm{Wu}, \mathrm{Y}$. (2010). Effects of perceived interactivity, perceived web assurance and disposition to trust on initial online trust. Journal of Computermediated Communication, 16(1), 1-26. 